\title{
A Study on the User's Value of the Smart Home Service in the Internet of Things Technology
}

\author{
SeongJeong Yoon ${ }^{1}$ and JongBae $\mathrm{Kim}^{2}$ \\ ${ }^{1}$ Author, Department of Business Administration, Kyunghee Univ, Seoul, \\ Korea, 02447 \\ ${ }^{2}$ Correspondent Author, Graduate School of Software, Soongsil University, Seoul, \\ Korea, 156743 \\ 1sj9416@naver.com, ${ }^{2} k j b 123 @ s s u . a c . k r$
}

\begin{abstract}
The Internet of Things (IoT) is becoming an increasingly integral part of our daily lives. In other words, IoT's smart home services are being used in various forms such as security systems, access control management systems, power management systems, and security systems. This study aims to find out more about the perceived value of smart home service to people. Previous research suggests that smart home services provide various values that include economy, automation, convenience of management, and stability. However, it is necessary to look for the most important value in terms of users' view in life because many people still perceive smart home services as being conceptual rather than realistic. This study was conducted to measure the actual value of the smart home service users. In this study, we can summarize the result of measuring the actual perceived value of users. Safety, manageability, agility, and automation are important when providing smart home services regardless of user type. Safety and agility have been found to be the most important factors for each user type in common. The type of user value is divided into original and derivative. The original value is perceived as the basic function of stability, economy, automation, and agility. The derived values generated from the basic functions are recognized as entertainment, relationship, and familiarity. Finally, this research intends to provide a clue to enhance sustainable usability reflecting the important values of smart home services.
\end{abstract}

Keywords: Internet of things, Smart home service, User's value, IoT trends

\section{Introduction}

Recently, many companies have been positively evaluating prospects for the Internet of Things [4][13]. Machina Research estimates that the global Internet of Things market will grow from $\$ 900$ billion in 2014 to $\$ 4.3$ trillion in 2024[6]. Cisco, a telecommunications company, estimates that in 2012, 8.6 billion of the 1.5 trillion objects will be connected to 8.7 billion. Gartner estimates that from 2012 to 2020, the smart home service market will grow by $25 \%$ each year, bringing Internet access to 50 billion items, $2.7 \%$ of the 1.8 trillion objects [8]. The following is a look at the movement of various countries on the Internet of Things. Germany is implementing a smart manufacturing innovation promotion policy called Industry 4.0, and the United Kingdom is supporting Hypercat, a "consortium of standardization of things Internet technology". Among the companies that offer smart home services based on Internet of Things technology, Google has Nest, Apple Homekit, Samsung SmartThings, LG SmartThingsQ, LG U + 's IoT @ home and SKT' s Smart [Home] service [15]. As such, the Internet of Things has not only expanded its market size but also launched various products. Recently, telecommunication companies and researchers have been working hard for quantitative and qualitative growth of Internet of Things. Korea 's LG U +' s IoT @ home service introduces IoT 
CCTV sensors, a security service, IoT door cams, IoT gas locks, energy management, home appliance management and pet feeding functions to manage access. In recent research trends, there are research on user value factors and user types of Internet service of things, and analysis of economic ripple effects of Internet of Things [22]. In addition, the convergence research of the Internet of Things and cloud computing has been growing more recently [16]. There are many studies on the value perspective of users in various studies [14]. This means that the conceptual value of the Internet of Things can be accepted, but there is a need for research on the practical use value. For example, smart home services are convenient and economical, but they are not compatible and manageable with other products. Therefore, it is necessary to clarify the user's perceived value of the user rather than the product value created by the telecommunication company through this study. Therefore, it is necessary to re-evaluate the user's actual value for smart home service. Based on the user value factors presented in the previous research, we will identify what factors are most important in the user's actual value. Through this, we will present the key factors that can realize the practical value of smart home service which is more intelligent one in the future.

\section{Literature Review}

\subsection{Internet of Things based Smart Home Service}

In this research, we used Google scalar search and trends to analyze research and trends related to the Internet of Things based smart home service. When we search for research on Internet of Things based Internet smart home service, it gave up about 20,200 results. In addition, Figure 1 shows that interest in smart home service is continuously increasing. The most relevant countries are the Philippines, Germany, the United States, Canada, and Singapore, and related search terms related to smart home service that appeared were smart TV, smart home security, home automation, smart home system, and Samsung. In addition, interest in smart home services has been growing rapidly since 2015. We are now launching a smart home service product and are developing a smart home service that has evolved continuously [9].

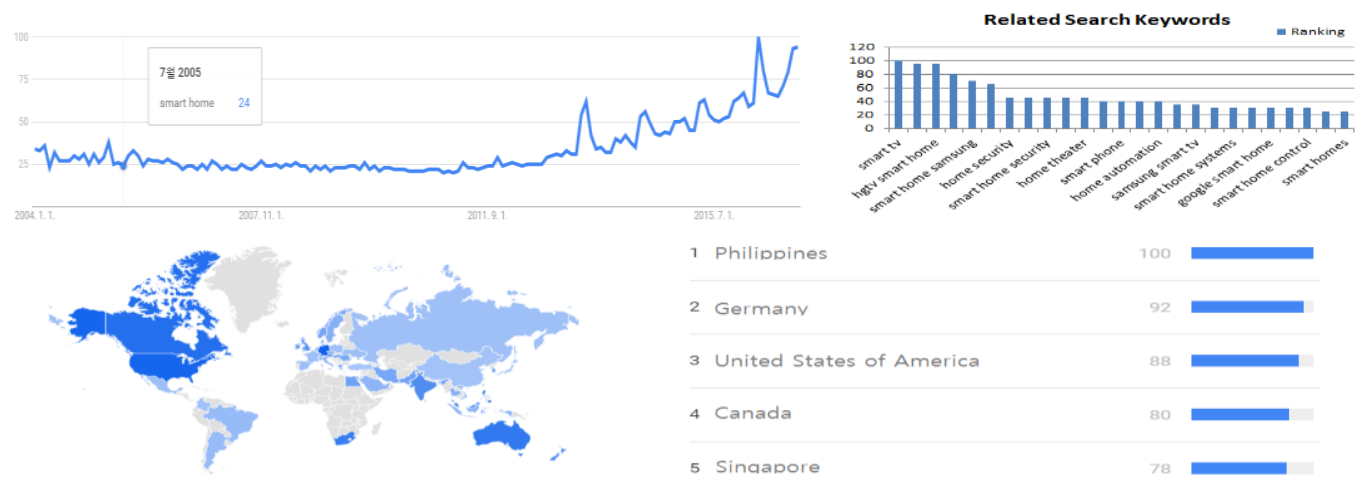

Figure 1. Smart Home Service Trends (Internet of Things)

Table 1 shows that various smart home service products are being released worldwide. Major smart home services include access control, power management, gas leak detection, security management, humidity and temperature sensing, fire detection, home appliances and remote operation and inspection services for heating and cooling systems. In the case of LG U + Home service, it provides a pet feeding service. Apple's HomeKit is launching a variety of IoT products to provide Lights \& Switches, Alarms \& Sensors, and Heating \& Cooling services. Samsung's SmartThings sells products in the form of Kits, Hubs, 
Sensors, and Outlets. LG's SmartThinQ is launching Smart Refrigerator and Smart Kitchen. SKT offers Smart Home SOS button, door sensor, gas locking system, and heating sensor [5].

Table 1. Smart Home Service by Company

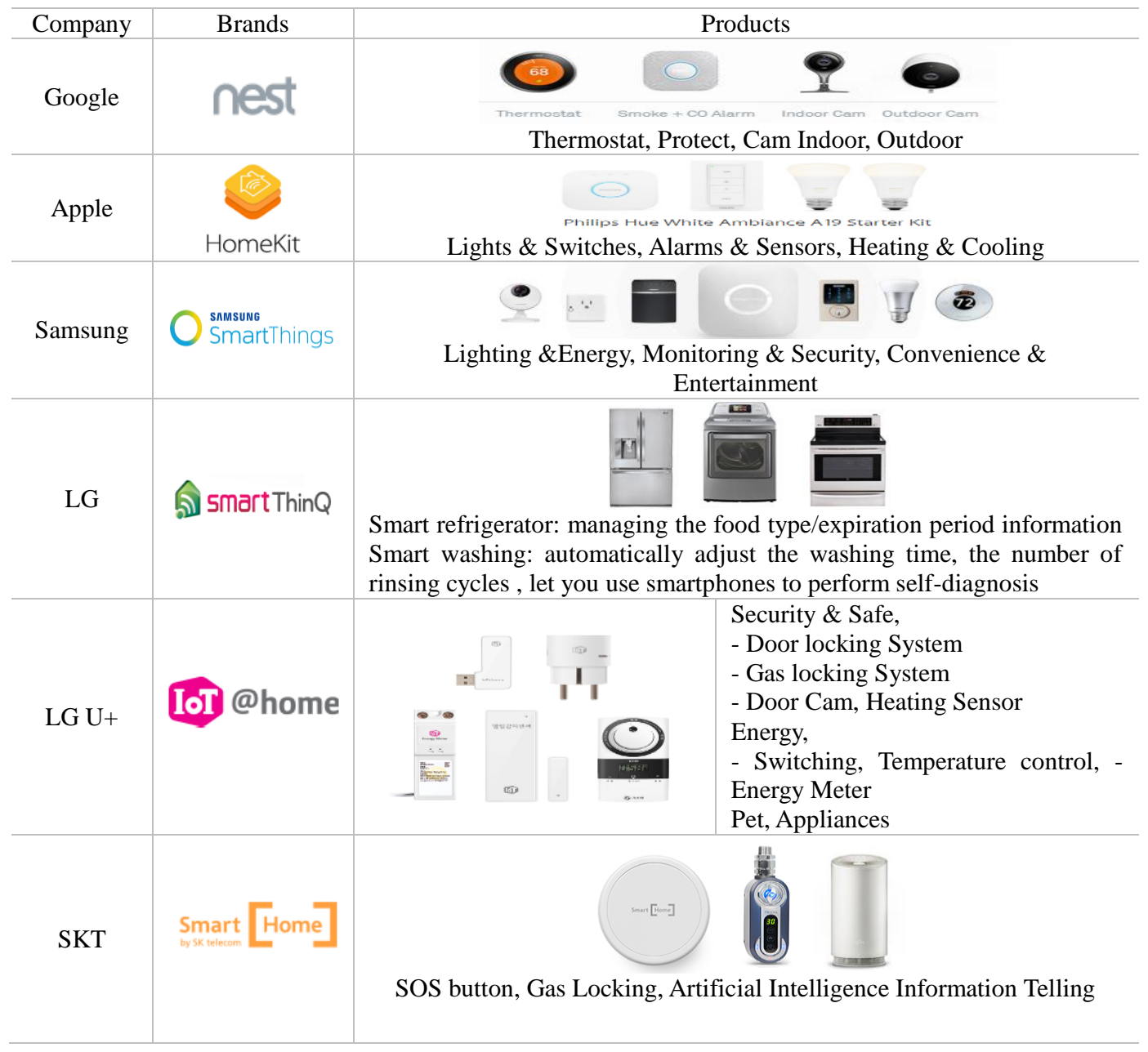

The following is a description of the trends of the research on the Internet of Things Smart Home Service. There are many technical research that implement smart home service, and major technologies such as big data, cloud computing, and peripheral devices converge [3][17] [21]. In this study, we do not focus on the study of technical implementation, but try to find out important factors that users value in a smart home service before implementing it. This is because, along with the launch of various smart home service products, it is necessary to fully reflect the qualitative value to satisfy the user's practical value.

\subsection{The Value of Smart Home Service Users}

In previous studies, the user value research of smart home service was examined by extracting user value items through potential value and focus group interview (FGI) through literature research [15]. In this study, it is suggested that the constituent concept consists of 13 factors by factor analysis of user value. Let us look at the method and results of the study by Park and Ryoo(2016) and the definition of each construct. First of all, in the literature study, the user value is defined as shown in Table 2 $[2][7][10][12][18][20]$. 
Table 2. User's Value Factors in the Literature [15]

\begin{tabular}{c|c|c}
\hline Family Unity & Ease of use & Information delivery \\
\hline Economic & Sociality & Information provision \\
\hline Management & Interoperability & Enjoyment \\
\hline Positive psychology & Communication & Acquaintance network familiarity \\
\hline Internalization & Time saving & Comfortability \\
\hline Simplicity & Reliability & Controllability \\
\hline Data security & Safety & Convenience \\
\hline Lifestyle customization & Stability & Compatibility \\
\hline Clarity & Usability & Home care \\
\hline Security & Meaningfulness & Scalability \\
\hline Cost reduction & Human friendly & Efficiency \\
\hline Accident prevention & Automation & Quickness \\
\hline Privacy & Information curation & \\
\hline
\end{tabular}

According to this study by Park and Ryoo(2016), the target group interviews consisted of 5 participants from 20-40 of the people who had used smart home service and conducted two sessions. Table 2 shows the user value for this.

\section{Table 3. User's Value Factors in Focus Group Interview [15]}

\begin{tabular}{c|c|c|c}
\hline Family & Consideration & Reliability & Self-efficacy \\
\hline Simplicity & Reward & Quickness Information & Safety \\
\hline Simplicity & Security & Accuracy & Connectivity \\
\hline Sensitivity & Cost saving & Intuitiveness & Comfort \\
\hline Economics & Privacy management & Familiarity & Ease \\
\hline Management & Privacy & Eco-friendliness & Compatibility \\
\hline Activeness & Refreshing & Unity & Call Monitoring \\
\hline Proficiency & Communication & Convenience & Home Care \\
\hline Cost & Time management & Learning & Scalability \\
\hline Clarity & Time reduction & Curiosity & Environmental Purification \\
\hline
\end{tabular}

In the study of Park and Ryoo(2016), 67 items were derived and presented by combining the literature value of the Internet of Things and the target group interview. This is the result of integrating similar items with 39 items in the literature study and 49 items in the target group.

\section{Table 4. User's Value Factors in the Literature, Focus Group Interview [15]}

Family affinity, family harmony, simplicity, emotion, economics, management, positive psychology, internalization, activeness, proficiency, simplicity, cost, data security, lifestyle customization, clarity, consideration, reward, security, Cost reduction, accident prevention, privacy control, privacy protection, ease of use, sociality, refreshment, interoperability, communication, time management, time reduction, Reliability, Fastness, Safety, Safety, Connectivity, Comfort, Bonding, Usability, Significance, Familiarity, Human Friendly, Automation, Spontaneous, Fun, Information Delivery, Information Curl, Accuracy, enjoyment, acquaintance network, intuitiveness, familiarity, environment friendliness, comfort, unity, controllability, convenience, comfort, convenience, learning ability, curiosity, compatibility, home monitoring, home care, scalability, environmental cleanup, efficiency

In the study of Park and Ryoo(2016), factor analysis of the Internet of Things user value of the items in Table 4 was analyzed as 13 factors. Factors are such as manageability, relationship, familiarity, extensibility, simplicity, entertainment, safety, economics, rewards, automation and quickness. However, it is necessary to rearrange the measurement variables satisfying the Factor Loading Value of 0.5 or more. Factor loading value 0.5 or more is re-summarized and described in the appendix. The definition of each 
factor is as follows. Manageability means that the user can manage the smart home service at any time from inside/outside to remotely. The relationship is defined as the ability to increase communication and consensus among family members of smart home service users. Familiarity refers to feeling familiar and comfortable to use, and scalability refers to the ability to link and expand with new devices, technologies, and services.

Simplicity refers to being easy and intuitive to use, and enjoyment refers to providing fun or pleasure while using it. Safety refers to the prevention and protection from accidents and external physical threats in advance. Economics refers to whether there is a benefit in terms of time and effort. Compensation refers to the ability to donate or share points by accumulating points by cost, labor, time and energy saving. Automation refers to the automatic proposal or execution of a service without any special effort of the user, and quickness means to be able to use it quickly at anytime, anywhere. Informality refers to the efficient use of appropriate information while using it. Lastly, environmentalism refers to managing temperature, humidity and air quality to achieve a more pleasant and comfortable life.

The above 13 factors are defined in the Park and Ryoo(2016) study. However, this study revealed only the user value factors for smart home services based on the Internet of Things, not the classification according to the characteristics of users. In addition, it is necessary to find out the priority of the user value according to such a user specification. This is because the user value differs according to the characteristics of users. If we give consistent value to smart home service without considering it, it is hard to secure usability expansion and intention of continuous use. In this paper, Lee et al (2015) describes four types of user types, their definition and usage motivation in the next chapter.

\subsection{Types of users on the Internet of Things}

Lee et al., (2015) previous study found that there are four types of Internet of Things users. The first type is an attractive Internet user and positive privacy type. The second type is defined as half-afflicted Internet of Things users and half-negative privacy types. The third type is limited Internet of Things users and error prevention presentation type, and the fourth type is negative Internet of Things users and private life type. Table 5 summarizes definitions and usage motives for each type [1] [14].

Table 5. Definition and Usage Motive by User's Type[14]

\begin{tabular}{|c|c|c|}
\hline User's Type & Definition & Usage Motive \\
\hline $\begin{array}{c}\text { Type } 1 \\
\text { Attractive Internet of Things } \\
\text { Users }+ \\
\text { Positive Privacy Type }\end{array}$ & $\begin{array}{l}\text { There is a positive aspect to the use of } \\
\text { internet of things, but there is a } \\
\text { tendency to require a device to protect } \\
\text { privacy. }\end{array}$ & $\begin{array}{l}\text { Internet of things, you can see the } \\
\text { work on the internet anytime and } \\
\text { anywhere without restriction of the } \\
\text { space and it works by sensing your } \\
\text { movement and has various } \\
\text { applications and convenience. }\end{array}$ \\
\hline $\begin{array}{c}\text { Type } 2 \\
\text { Antipathetic Internet of } \\
\text { Things users + } \\
\text { Antipathetic Privacy Type }\end{array}$ & $\begin{array}{l}\text { There is a tendency to have a negative } \\
\text { aspect of internet of things use and a } \\
\text { problem element that violates privacy. }\end{array}$ & $\begin{array}{l}\text { These users are extremely aware of } \\
\text { the fact that I have a strong despair } \\
\text { over the problem of privacy invasion } \\
\text { rather than the digital advantage of } \\
\text { the Internet of things. }\end{array}$ \\
\hline $\begin{array}{c}\text { Type } 3 \\
\text { Restricted Internet of Things } \\
\text { users }+ \\
\text { Error-proof presentation type }\end{array}$ & $\begin{array}{l}\text { There is a tendency to perceive that } \\
\text { there is a positive aspect to the use of } \\
\text { internet of things but it is necessary to } \\
\text { prevent the provision of inaccurate } \\
\text { information. }\end{array}$ & $\begin{array}{l}\text { These users are positive about the } \\
\text { convenience of remote control and } \\
\text { remote use in Internet use of things, } \\
\text { but I am concerned about inaccurate } \\
\text { information transmission. }\end{array}$ \\
\hline $\begin{array}{c}\text { Type } 4 \\
\text { Negative Internet of Things } \\
\text { users }+ \\
\text { Private life }\end{array}$ & $\begin{array}{l}\text { There is a negative aspect to the } \\
\text { internet of things use of things and a } \\
\text { type that tends to perceive the internet } \\
\text { of things with many devices of privacy } \\
\text { violation. }\end{array}$ & $\begin{array}{l}\text { These users perceived conflicts } \\
\text { between the privacy matter and the } \\
\text { public interest and privacy rights in } \\
\text { the internet of things use. }\end{array}$ \\
\hline
\end{tabular}


In this study, Lee et al., (2015) suggested that the four types presented in the study are highly subjective areas of human beings, so they applied the Q methodology to study them objectively [19]. Type 1 has a positive perception of Internet of Things, while types 2 and 4 have an antipathetic or negative perception of Internet of Things use. Or if there is inaccurate information, it is a type that recognizes that prevention is necessary, and belongs to a category that thinks negative about privacy invasion. In other words, type 1 has a positive perception of Internet of Things use and privacy, while the other types have negative perceptions. In this study, we also investigate whether this type appears in the use of smart home service. We also want to verify whether there is a difference in the user value suggested by Park and Ryoo(2016). The purpose of this study is to clarify whether the negative or positive perception of the Internet of Things is different between the use of intention and the intention of continuous use and to find out whether the smart home service perceives the most problematic security problem.

\section{Methodology}

In this study, we will examine the difference in the user value of Internet of things. First of all, a questionnaire based on the result of factor analysis of user value in the study of Park \& Ryoo (2016) will be constructed and the priority of each factor will be investigated. However, factor analysis suggested by Park \& Ryoo (2016) will be carried out by removing less than 0.5 level. In the previous research, 13 factors were suggested, but if the factor less than 0.5 level is removed, it is reduced to 10 factors [11].

That is, we will measure the attributes of manageability, relationship, familiarity, scalability, simplicity, entertainment, safety, economy, automation, and agility. We will also measure the priority for 10 attributes. We will use the multidimensional scaling method to analyze the four types of users presented by Lee et al., (2015) and present the results.

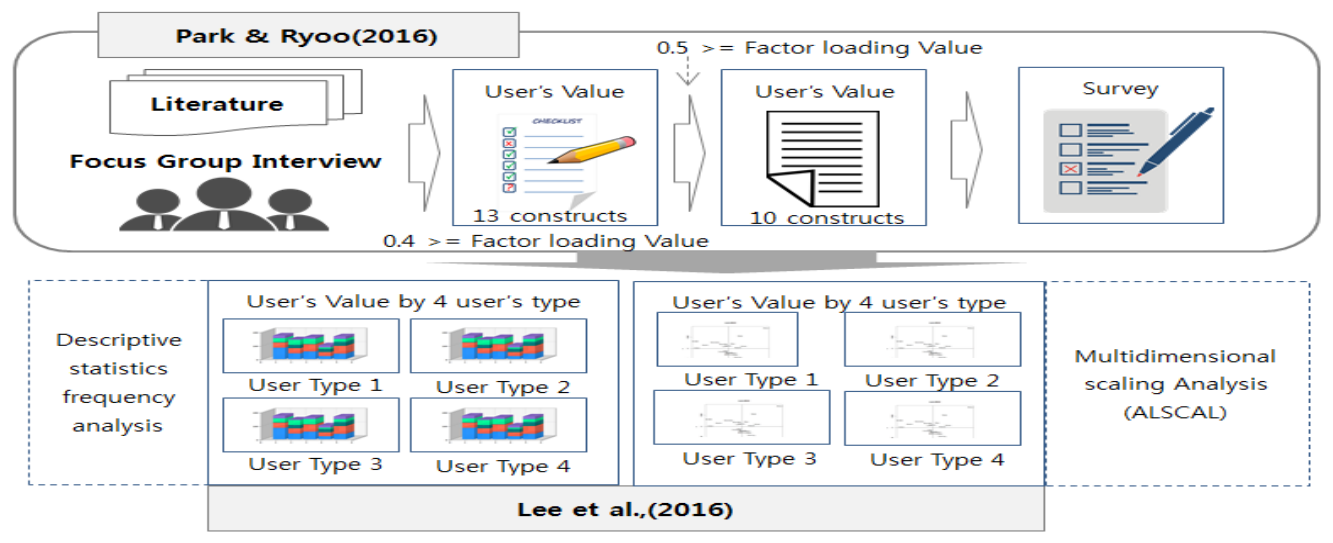

Figure 2. Value Analysis Procedure by User Type

For factor analysis tables see Appendix. In this study, factor loading value of less than 0.4 is not applied to measure for user's value.

\section{Analysis}

In this study, a total of 120 subjects were surveyed. Also, we showed the publicity video about the smart home service before the questionnaire. In the questionnaire, the product catalogs and explanations for the smart home service were written and understood. The total constructs factor of each questionnaire was 10 , and the detailed measurement items of each construct's concept were corresponded to the importance rank of user value. In this study, we selected four types of users proposed in the research methodology. We 
analyze the overall user value and analyze the user value according to four user types. We analyzed the frequency of the constructs and analyzed the degree of distance between constructs and respondents through multidimensional scaling analysis. In the multidimensional scaling analysis, it is analyzed as ALSCAL because it is a matrix composed of attributes and respondents [11].

\subsection{Demographic Characteristics}

Looking at the characteristics of smart home service users, $53.3 \%$ of males and $46.7 \%$ of females are in the category. In the age group, $70 \%$ of them are in their $20 \mathrm{~s}$, followed by $25.0 \%$ of their $40 \mathrm{~s}$. Most of the respondents in this study occupy $57 \%$ of the occupations in the IT industry. Major use products use intrusion security function with $33.3 \%$. In addition, it was found that $20.0 \%$ was used for door lock function and air conditioning control function, respectively. Also, type 1, which is positive for the Internet of Things, was the most common type (63.3\%), and users (25.0\%) were most aware of the Internet of Things and personal privacy. It can be seen that there is more positive perception than the negative perception of Internet of Things use.

Table 6. Demographic Statistics

\begin{tabular}{|c|c|c|c|c|c|c|c|}
\hline \multicolumn{2}{|c|}{ Classification $(\mathrm{n}=120)$} & Frequency & $\begin{array}{l}\text { Ratio } \\
(\%)\end{array}$ & \multicolumn{2}{|c|}{ Classification $(n=120)$} & Frequency & $\begin{array}{c}\text { Ratio } \\
(\%)\end{array}$ \\
\hline \multirow{2}{*}{ Gender } & Male & 64 & 53.3 & \multirow{6}{*}{ Job } & Student & 20 & 17 \\
\hline & Female & 56 & 46.7 & & IT Industry & 68 & 57 \\
\hline \multirow{4}{*}{ Age } & $20 \mathrm{~s}$ & 84 & 70.0 & & Service Industry & 12 & 10.0 \\
\hline & $30 \mathrm{~s}$ & 4 & 3.3 & & Medical / Hospital & 2 & 1.7 \\
\hline & 40 & 30 & 25.0 & & Manufacturing & 12 & 10.0 \\
\hline & 50 s or higher & 2 & 1.7 & & Employee & 6 & 5.0 \\
\hline \multirow{5}{*}{$\begin{array}{l}\text { Main } \\
\text { Used } \\
\text { Products }\end{array}$} & Gas Locking & 9 & 7.5 & \multicolumn{2}{|c|}{ Intrusion security } & 40 & 33.3 \\
\hline & Door Locking & 24 & 20.0 & \multicolumn{2}{|c|}{ Heating/Cooling control } & 24 & 20.0 \\
\hline & Smart TV & 6 & 5.0 & \multicolumn{2}{|c|}{ Temperature/humidity control } & 6 & 5.0 \\
\hline & Smart Audio & 1 & .8 & \multicolumn{2}{|c|}{ Go out management } & 6 & 5.0 \\
\hline & Power Meters & 4 & 3.3 & & & & \\
\hline \multirow{4}{*}{$\begin{array}{l}\text { User's } \\
\text { Type }\end{array}$} & \multicolumn{5}{|c|}{ Type 1: Attractive Internet of Things Users + Positive Privacy } & 76 & 63.3 \\
\hline & \multicolumn{5}{|c|}{ Type 2: Antipathetic Internet of Things users + Antipathetic Privacy } & 6 & 5.0 \\
\hline & \multicolumn{5}{|c|}{ Type 3: Restricted Internet of Things users + Error-proof presentation } & 8 & 6.7 \\
\hline & \multicolumn{5}{|c|}{ Type 4: Negative Internet of Things users + Private life } & 30 & 25.0 \\
\hline
\end{tabular}

\subsection{User value Frequency Analysis (by user type)}

As a result of frequency analysis of user value of Internet of Things based smart home service, stability, manageability, agility, and automation were found to be the most important factors. The rapidity common to user types 1 to 4 is in the 4 th place among the total 10. In addition, safety is ranked first and second in user types 2 to 4 .

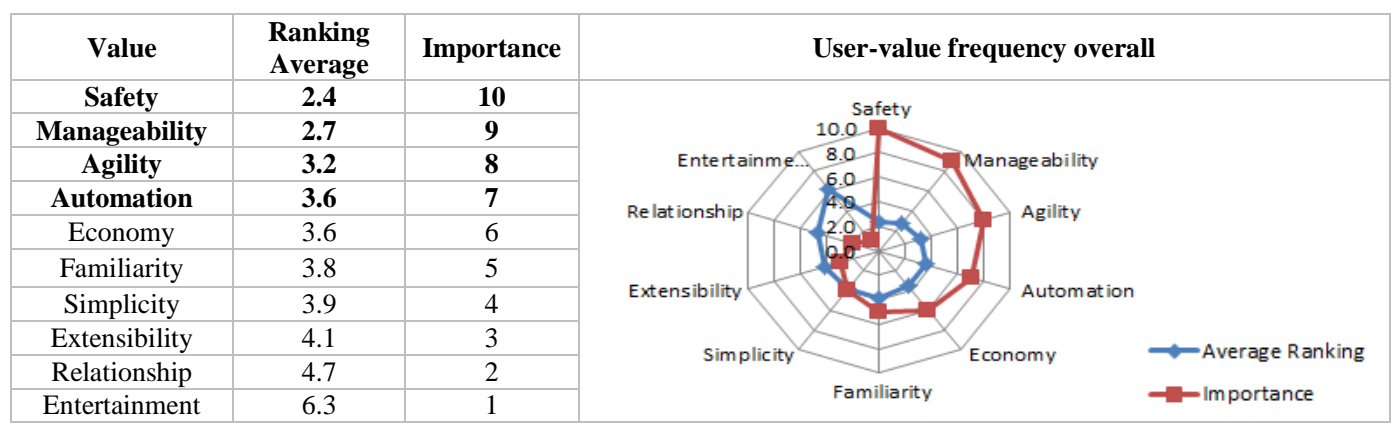

Figure 3. User-value Frequency Analysis(overall) 
The results of analyzing user value for four types of Internet of Things users are as follows. User type 1 was defined as an attractive Internet of Things user and a positive privacy type. Recognizing that user type 1 is an important factor in smart home service, it shows the results of safety, manageability, agility, and economy. Regardless of the type of users, the overall value of the user's value was examined. The economics defined in the previous study are defined as "the value that the user desires to gain in terms of time and effort, including cost, while using the Internet service of objects". In other words, electricity, heating and cooling, and security management are telling us whether utility bills are actually decreasing in the case of non-integrated management.

User type 2 is defined as a half-life object Internet of Things user and half-life privacy type. User type 2 recognizes the importance of automation, speed, economy, and familiarity in that order. The use of user type 2 in the existing research is as follows: "It is extremely disconcerting about the problem of privacy invasion rather than the digital advantage of Internet of things". In other words, the smart home service must analyze the life pattern beyond the basic smart service and have a part to manage it by oneself. In other words, it means that a smart home service should not be called a smart home service by connecting multiple systems.

\begin{tabular}{|c|c|c|c|c|c|}
\hline \multicolumn{3}{|c|}{ User's Type 1} & \multicolumn{3}{|c|}{ User's Type 2} \\
\hline User's Value & $\begin{array}{l}\text { Ranking } \\
\text { Average }\end{array}$ & importance & User's Value & $\begin{array}{l}\text { Ranking } \\
\text { Average }\end{array}$ & importance \\
\hline Safety & 2.5 & 10 & Automation & 2.0 & 10 \\
\hline Manageability & 2.7 & 9 & Agility & 2.0 & 9 \\
\hline Agility & 3.3 & 8 & Economy & 2.3 & 8 \\
\hline Economy & 3.4 & 7 & Familiarity & 2.7 & 7 \\
\hline Automation & 3.6 & 6 & Safety & 2.7 & 6 \\
\hline Familiarity & 3.7 & 5 & Manageability & 3.0 & 5 \\
\hline Simplicity & 3.8 & 4 & Relationship & 3.0 & 4 \\
\hline Extensibility & 4.4 & 3 & Extensibility & 3.0 & 3 \\
\hline Relationship & 4.7 & 2 & Entertainment & 3.0 & 2 \\
\hline Entertainment & 6.7 & 1 & Simplicity & 3.3 & 1 \\
\hline $\begin{array}{l}\text { Entertainn } \\
\text { Relationship }\end{array}$ & Automati & $\rightarrow$ Average Ranking & Relatio & Economy & $\begin{array}{l}\text {-Average Ranking } \\
\text {-Importance }\end{array}$ \\
\hline
\end{tabular}

Figure 4. User-value Frequency User's Type 1, 2

User type 3 is defined as a restricted Internet of Things user and error-proof presentation type. The use motives presented in the previous research are defined as "concerns about providing convenience for remote control and remote use in the Internet use of objects, but worry about inaccurate information delivery". User type 3 is recognizes importance in order of manageability, stability, agility, and familiarity. The concept of management is consistent with the definitions given in previous studies and the concepts measured in this study. In other words, it has the same result as previous studies in that there is motivation to use for remote control and use.

User type 4 is a negative object Internet user and a person who is cautious about 
privacy. It has been concluded that user type 4 recognizes importance in order of safety, simplicity, agility, and automation. User type 4 can be interpreted as the fact that the factor of safety of smart home service is the most important is that there is no trust in stability. Also, the reason for recognizing the importance of simplicity is that it is not easy and intuitive to use smart home service, and the information provided is also clear and not concise.

\begin{tabular}{|c|c|c|c|c|c|}
\hline \multicolumn{3}{|c|}{ User's Type 3} & \multicolumn{3}{|c|}{ User's Type 4} \\
\hline User's Value & $\begin{array}{l}\text { Ranking } \\
\text { Average }\end{array}$ & importance & User's Value & $\begin{array}{l}\text { Ranking } \\
\text { Average }\end{array}$ & importance \\
\hline Manageability & 2.3 & 10 & Safety & 1.3 & 10 \\
\hline Safety & 2.5 & 9 & Simplicity & 3.0 & 9 \\
\hline Agility & 3.1 & 8 & Agility & 3.5 & 8 \\
\hline Familiarity & 3.4 & 7 & Automation & 3.8 & 7 \\
\hline Extensibility & 3.5 & 6 & Manageability & 4.0 & 6 \\
\hline Automation & 3.8 & 5 & Extensibility & 4.0 & 5 \\
\hline Economy & 4.1 & 4 & Economy & 4.0 & 4 \\
\hline Simplicity & 4.3 & 3 & Entertainment & 5.5 & 3 \\
\hline Relationship & 4.5 & 2 & Relationship & 6.8 & 2 \\
\hline Entertainment & 5.9 & 1 & Familiarity & 7.0 & 1 \\
\hline $\begin{array}{r}\text { Entertainn } \\
\text { Relationship }\end{array}$ & xtensibili & 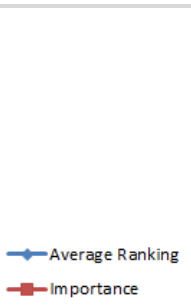 & ainment & $\begin{array}{l}\text { licity } \\
\text { Agility }\end{array}$ & $\rightarrow$ Average Ranking \\
\hline
\end{tabular}

Figure 5. User-value Frequency User's Type 3, 4

\subsection{Multi-dimensional Analysis (by user type)}

In this study, multidimensional scaling analysis was conducted to measure the importance of ten Internet of Things users' value. The multidimensional scaling analysis is the one-dimensional and two-dimensional representation of the differences between the ten user values and the respondents using the Euclidean distance. There are two methods of multidimensional scaling: ALSCAL and PROXSCAL. In the case of ALSCAL, the matrix type performs a multidimensional scaling analysis when there is an attribute in the horizontal direction and respondents in the vertical direction [11]. In this study, data were collected with ten user values (horizontal attributes) and respondents. Also, the scale of data collection was measured by ordinal scale.

Table 7. Evaluation of Model fit by Stress Value

\begin{tabular}{|c|c|}
\hline S-stress value & Fit of data \\
\hline 0.2 or more & Very bad \\
\hline 0.2 & bad \\
\hline 0.1 & Acceptable \\
\hline 0.05 & Good \\
\hline 0.025 & Very Good \\
\hline 0 & Perfect \\
\hline
\end{tabular}


However, PROXSCAL refers to a matrix in which both rows and columns have certain attributes. Therefore, this study selected ALSCAL method. In addition, the multidimensional scaling of the data is assessed using the same criteria as in table 7 . Figure 6 shows the difference between the distance in 10 user values and the distance between respondents. The closer the distance between the derived properties of the map in Figure 6, the closer the user perceived value. In other words, respondents perceived similarity in terms of automation, safety, agility, and economy. Entertainment, relationship, extensibility, familiarity, simplicity, and manageability were also perceived as attributes of the group. Most of the 120 respondents are aware of the moderate user value of the attributes of the two groups. In order to clarify the interpretation, Figure 3 shows that the importance of user value to safety, manageability, agility, automation, and economy is high. In addition, the fitness of the data was found to be 37 times repetitive performance, and the 37th improvement in the figure 6 was 0.00100 (perfect model fit satisfied).

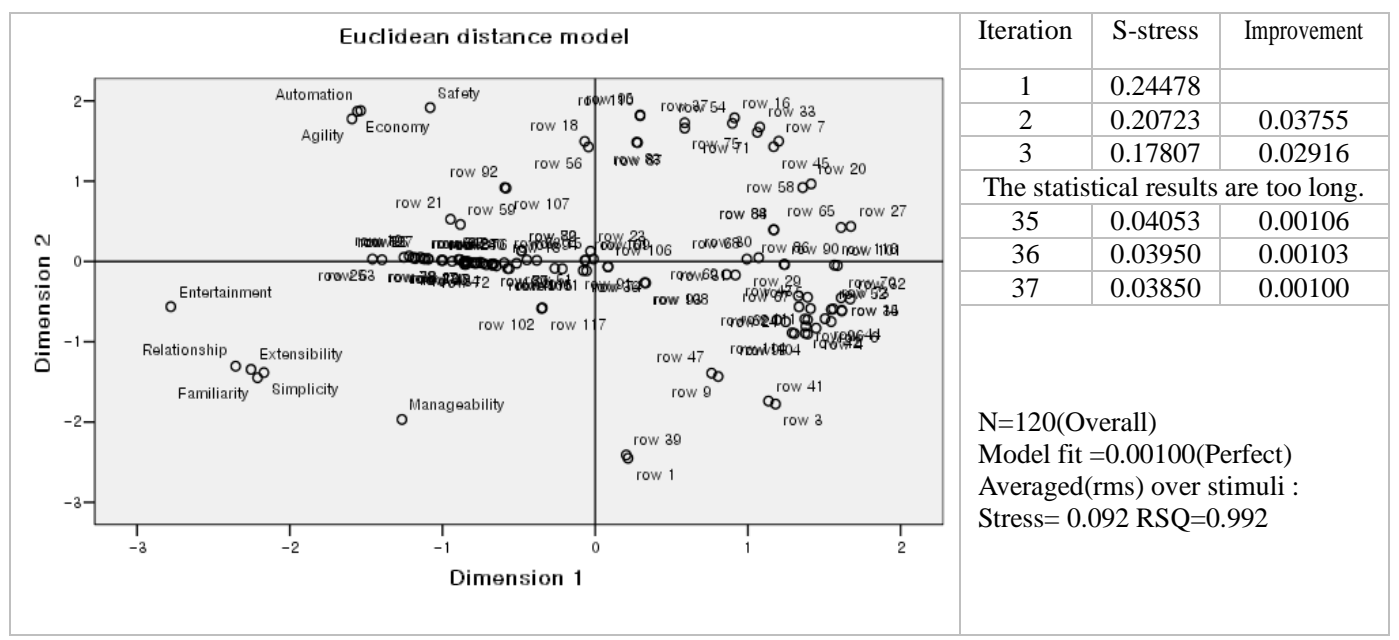

Figure 6. User-value Multidimensional Scaling Analysis (overall)

In the multidimensional scaling analysis, the results are difficult to grasp in Figure 2 4. For example, in Figure 6, it can be seen how smart home service user values have similarities and which similar groups are formed. Figure 6 shows that safety, automation, agility, and economy are identified as similar user value groups, and manageability, simplicity, familiarity, extensibility relationship, and entertainment are further divided into similar groups. The value of safety, automation, agility, and economy is seen as a value that must be delivered intrinsically through the use of smart home services, and groups such as relationships, familiarity, and entertainment must have value derived from their original user value. Most respondents show that both the original value and the derived value are important. Looking at user type 1, another similarity group has emerged, such as similarity groups for economy, automation, agility and safety, and entertainment, extensibility, relationship, familiarity, simplicity, and management. All users and user type 1 created the same type of similarity group. Respondents also say it is important for both similarity groups. 


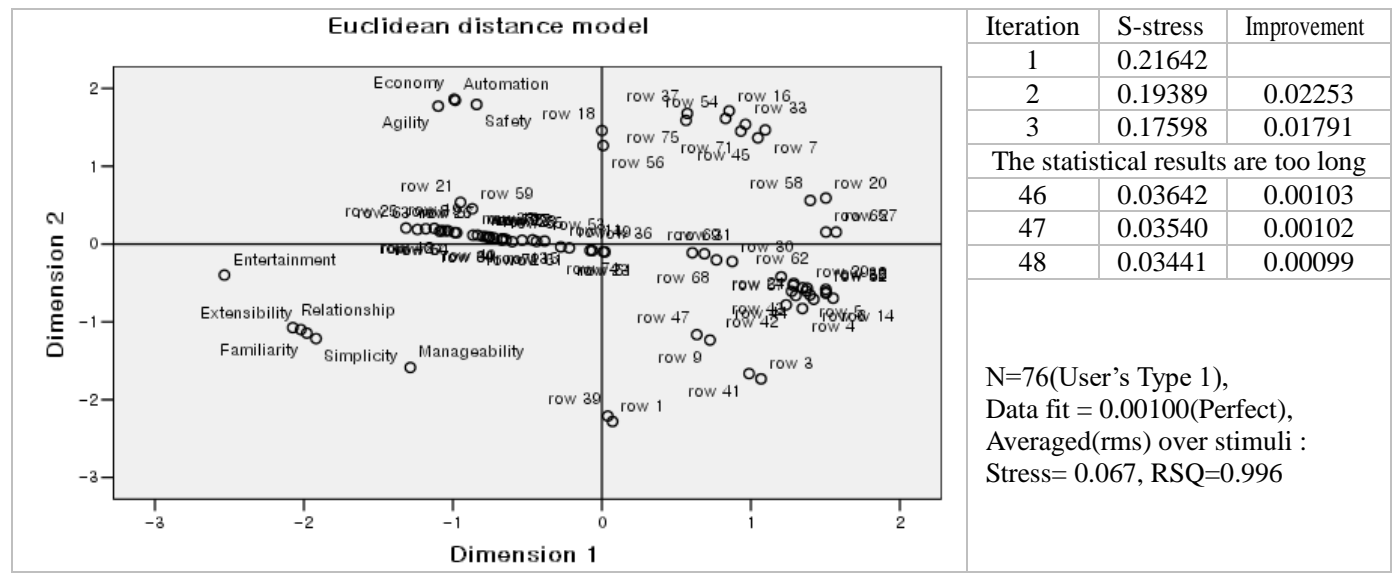

Figure 7. User-value Multidimensional Scaling Analysis (User's Type 1)

User type 2 recognizes simplicity, relationship, entertainment, and familiarity as the first similarity, and recognizes expandability, manageability, and safety as the second similarity group. Also, it can be seen that the automation, the agility, and the economy are recognized as the third similarity group. User type 2, which is an antisocial object Internet of Things user, perceives the third similarity as important in two out of six people, while the other two recognize that both first and second similarity are important. The other two were found to recognize and recognize the third similarity. In other words, smart home service that reflects automation, agility, and economy considerations should be provided to users of antisocial objects.

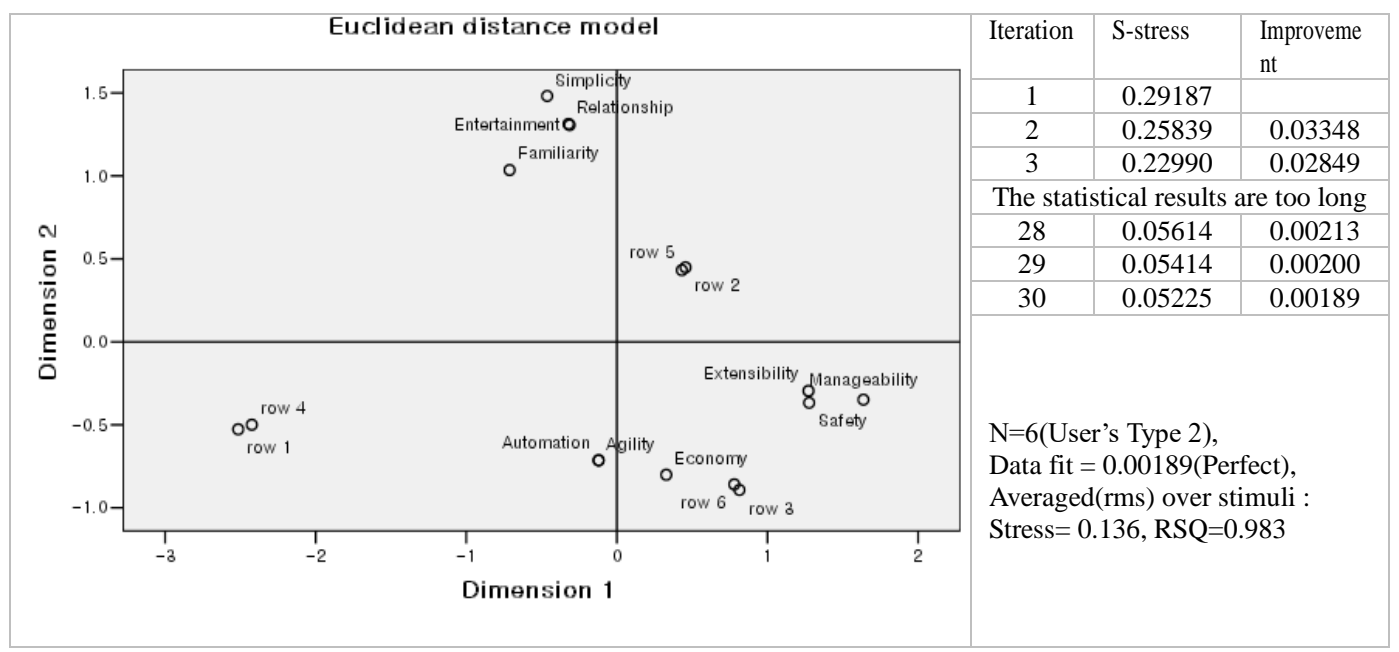

\section{Figure 8. User-value Multidimensional Scaling Analysis (User's Type 2)}

User type 3 has 10 different user value factors, so there are no similar characteristics. However, it recognizes that it is important for manageability, economy, and automation. It seems that the user expects to provide high quality service for smart home. 


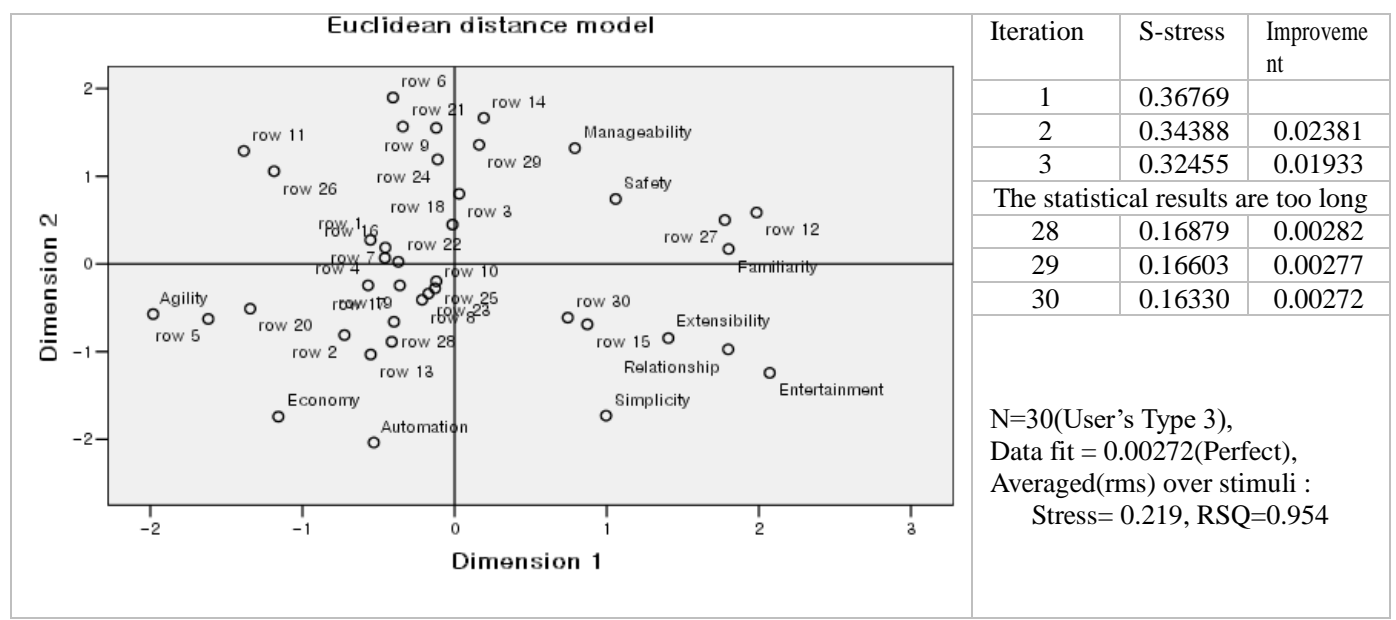

Figure 9. User-value Multidimensional Scaling Analysis (User's Type 3)

Finally, user type 4 recognizes entertainment, relationship, and familiarity as a negative similarity value characteristic, and sees simplicity, manageability, extensibility, and economy as the second similar value characteristic. Safety is also considered as the third similar value characteristic. Most users recognize that safety is important.

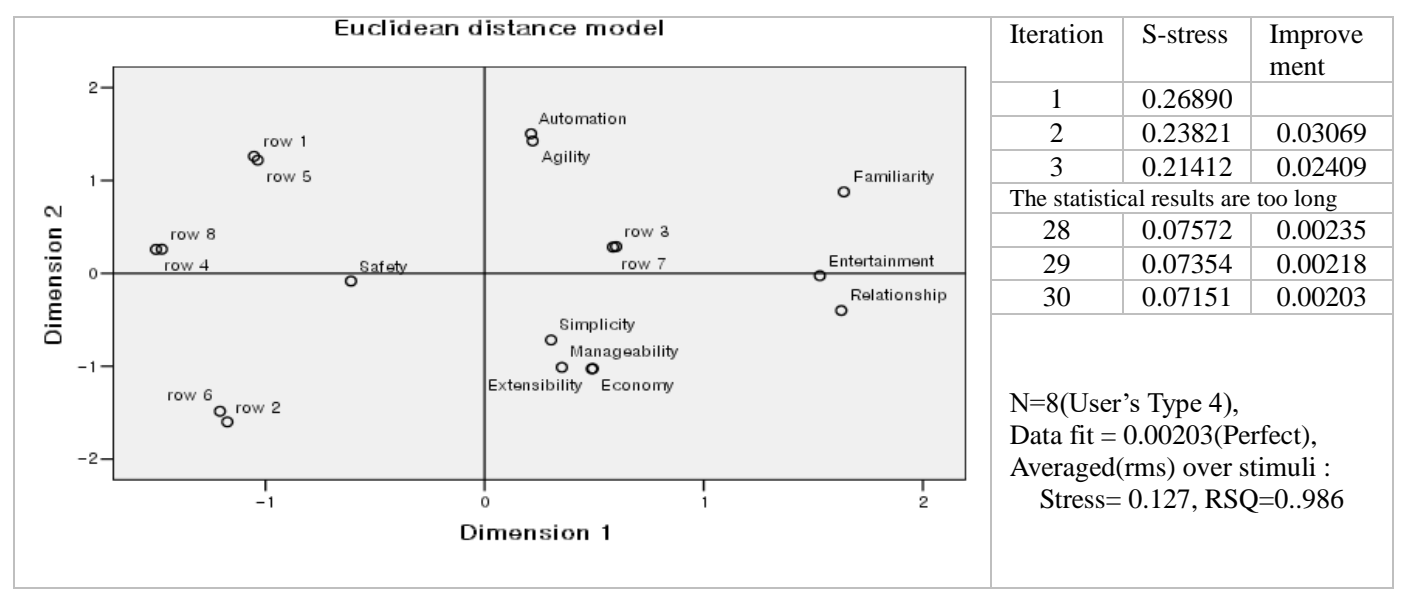

Figure 10. User-value Multidimensional Scaling Analysis (User's Type 4)

\section{Results \& Discussion}

The purpose of this study is to find out the important factors of user value of smart home service based on the Internet of Things. A summary of the results is as follows. First, Figure 2 shows that safety, manageability, agility, and automation are the highest regardless of user type. The results of Park \& Ryoo's study (2016) will be interpreted with the definition of user value factors. "Safety is the value that users want to prevent and protect against accidents or external physical threats that may occur in a specific space while using the Internet of Things service." Manageability is defined as "the value that the user desires to manage the situation anytime and anywhere remotely, both internally and externally, while using the object Internet of Things service". Agility is presented as "the value that users want to use their Internet services instantly and quickly, anywhere, anytime". Finally, automation is defined "to collect and analyze information related to user's life pattern, usage context, environmental condition, etc. And provide customized object Internet of Things service to users". As a result, it is expected that the most important factors to be considered in the smart home service based on the Internet of 
things are beyond the physical, temporal, and spatial limitations and to prevent them from being protected against various threats in daily life. In order to realize this, it can be managed regardless of physical location or time, and it can be understood that it must be processed promptly at the same time. In particular, the results suggest that a smart home service should have a customized service. This means that the pattern of the management data for the smart home service is analyzed, and it is fed back to automate so that human intervention is gradually reduced and there is a part to be automatically managed.

\section{Implications}

The major academic and practical implications of this study are as follows. The academic implications are as follows: First, in the previous research, only the factors related to the user value of the Internet were extracted. There were no studies to empirically analyze this. In this paper, we propose an analytical method to extend the existing research to find out what kind of user value is important in the field of smart home service. Second, the characteristics of users who use the Internet of things have been revealed in previous studies. However, it is difficult to find out "So What?" In this paper, we present a multidimensional analytical method for identifying user value by user characteristics. Practical implications are summarized as follows. First, it is necessary to fully reflect the needs of users until the smart home product is produced and provided as a service.

Many of the products have already reflected many of these needs, namely the concept of user value. But why is the smart home product still the Internet of Things? I cannot answer the answer. This is because the empirical analysis does not specifically reflect smart home products in practice. Therefore, in this study, it can be said that the value of real appreciation can be presented beyond the concept value that was introduced when the product was launched. Second, in a smart home service provider, it is necessary to periodically evaluate the 10 factors or more values presented in this study. In this study, smart home service has provided intelligent basis beyond smart. Third, we have proposed qualitative improvements that enable more people to use and continue to use smart home services.

\section{Limitations and Future Research}

The Internet of Things is not connected to certain areas only. Things The Internet of Things will have to move from one area to another and to the rest of the world. In this study, only the local part of the smart home service was surveyed in Korea. As a result, the value of Internet-based smart home services in Korea is not equally applied to other countries. In order to advance domestic smart home services overseas, it is necessary to reevaluate the user value of overseas users and the types of users may be different. However, it is still valid in the methodology presented in this study. Future research needs to compare user values and user types in various countries.

\section{Conclusions}

This study is not intended to simply improve the quality of smart home services. It also does not mean that you need to reflect these surveyed values on smart home services because of the different characteristics of users. Through this study, it is necessary to continue the research to reduce the difference between the conceptual value and the actual value that users feel like the smart home service based on Internet of things. It is very important to investigate each characteristic as in the previous studies. At the same time, however, it is necessary to provide specific clues that will reflect this to producers such as smart home services. This study not only identifies the type of user but also the type of similarity to user value. This suggests a part that can provide not only the original value 
and function of smart home service, but also the derivative value and function. Through this study, we hope that smart home users as well as producers can share the same value.

\section{Appendix}

Factor Analysis Tables [15]

\begin{tabular}{|c|c|c|c|c|c|c|c|c|c|c|c|c|c|}
\hline Factor & $\mathbf{1}$ & 2 & 3 & 4 & 5 & 6 & 7 & 8 & 9 & 10 & 11 & 12 & 13 \\
\hline \multicolumn{14}{|l|}{ Manageability } \\
\hline Automation & 0.710 & & & & & & & & & & & & \\
\hline Connectivity & 0.694 & & & & & & & & & & & & \\
\hline $\begin{array}{r}\text { Home } \\
\text { monitoring }\end{array}$ & 0.690 & & & & & & & & & & & & \\
\hline Usability & 0.681 & & & & & & & & & & & & \\
\hline $\begin{array}{r}\text { Accident } \\
\text { prevention }\end{array}$ & 0.677 & & & & & & & & & & & & \\
\hline Management & 0.670 & & & & & & & & & & & & \\
\hline Home care & 0.545 & & & & & & & & & & & & \\
\hline $\begin{array}{r}\text { Time } \\
\text { management }\end{array}$ & 0.544 & & & & & & & & & & & & \\
\hline \multicolumn{14}{|l|}{ Relationship } \\
\hline Family harmony & & 0.826 & & & & & & & & & & & \\
\hline Family affection & & 0.807 & & & & & & & & & & & \\
\hline $\begin{array}{r}\text { Strengthening } \\
\text { bond }\end{array}$ & & 0.723 & & & & & & & & & & & \\
\hline Emotion & & 0.713 & & & & & & & & & & & \\
\hline Sociality & & 0.681 & & & & & & & & & & & \\
\hline Communication & & 0.650 & & & & & & & & & & & \\
\hline Consideration & & 0.576 & & & & & & & & & & & \\
\hline $\begin{array}{r}\text { Acquaintance } \\
\text { network }\end{array}$ & & 0.513 & & & & & & & & & & & \\
\hline \multicolumn{14}{|l|}{ Familiarity } \\
\hline Human-Friendly & & & 0.605 & & & & & & & & & & \\
\hline Comfortable & & & 0.570 & & & & & & & & & & \\
\hline \multicolumn{14}{|l|}{ Extensibility } \\
\hline Compatibility & & & & 0.715 & & & & & & & & & \\
\hline Unity & & & & 0.639 & & & & & & & & & \\
\hline Controllability & & & & 0.613 & & & & & & & & & \\
\hline \multicolumn{14}{|l|}{ Simplicity } \\
\hline Conciseness & & & & & 0.758 & & & & & & & & \\
\hline Convenience & & & & & 0.783 & & & & & & & & \\
\hline Simplicity & & & & & 0.632 & & & & & & & & \\
\hline Ease of use & & & & & 0.603 & & & & & & & & \\
\hline \multicolumn{14}{|l|}{ Entertainment } \\
\hline Curiosity & & & & & & 0.676 & & & & & & & \\
\hline Proficiency & & & & & & 0.522 & & & & & & & \\
\hline Fun & & & & & & 0.519 & & & & & & & \\
\hline Learning & & & & & & 0.506 & & & & & & & \\
\hline \multicolumn{14}{|l|}{ Safety } \\
\hline $\begin{array}{r}\text { Privacy } \\
\text { management }\end{array}$ & & & & & & & 0.704 & & & & & & \\
\hline $\begin{array}{r}\text { Privacy } \\
\text { protection }\end{array}$ & & & & & & & 0.638 & & & & & & \\
\hline
\end{tabular}




\begin{tabular}{|c|c|c|c|c|c|c|c|c|c|c|c|c|c|}
\hline Security & & & & & & & 0.539 & & & & & & \\
\hline \multicolumn{14}{|l|}{ Economy } \\
\hline Refreshing & & & & & & & & 0.587 & & & & & \\
\hline Cost-saving & & & & & & & & 0.567 & & & & & \\
\hline Comfort & & & & & & & & 0.522 & & & & & \\
\hline \multicolumn{14}{|l|}{ Compensation } \\
\hline Intuitiveness & & & & & & & & & 0.466 & & & & \\
\hline Compensation & & & & & & & & & 0.460 & & & & \\
\hline Consideration & & & & & & & & & 0.445 & & & & \\
\hline Clarity & & & & & & & & & 0.406 & & & & \\
\hline \multicolumn{14}{|l|}{ Automation } \\
\hline Active & & & & & & & & & & 0.686 & & & \\
\hline Internalized & & & & & & & & & & 0.567 & & & \\
\hline Spontaneous & & & & & & & & & & 0.545 & & & \\
\hline \multicolumn{14}{|l|}{ Agility } \\
\hline Time reducing & & & & & & & & & & & 0.672 & & \\
\hline Agility & & & & & & & & & & & 0.481 & & \\
\hline \multicolumn{14}{|l|}{$\begin{array}{l}\text { Information } \\
\text { provability }\end{array}$} \\
\hline $\begin{array}{r}\text { Information } \\
\text { provision }\end{array}$ & & & & & & & & & & & & 0.496 & \\
\hline $\begin{array}{r}\text { Information } \\
\text { curation }\end{array}$ & & & & & & & & & & & & 0.453 & \\
\hline \multicolumn{14}{|l|}{ Environmental } \\
\hline $\begin{array}{r}\text { Environmental } \\
\text { cleanup }\end{array}$ & & & & & & & & & & & & & 0.528 \\
\hline Eigen Value & 7.827 & 7.459 & 3.631 & 3.247 & 3.192 & 3.070 & 2.682 & 2.321 & 2.071 & 2.033 & 1.966 & 1.717 & 1.390 \\
\hline $\begin{array}{l}\text { Cumulative } \\
\text { Variance }\end{array}$ & 11.682 & 22.814 & 28.233 & 33.080 & 37.544 & 42.426 & 49.893 & 49.893 & 52.985 & 56.019 & 58.953 & 61.516 & 63.590 \\
\hline Cronbach's $\alpha$ & 0.921 & 0.903 & 0.863 & 0.799 & 0.787 & 0.744 & 0.743 & 0.704 & 0.711 & 0.730 & 0.666 & 0.638 & \\
\hline
\end{tabular}

\section{References}

[1] Abdullahi Arabo, Ian Brown, Fadi El-Moussa.(2012). Privacy in the age of Mobility and Smart Devices in Smart Homes, ASE/IEEE International Conference on Social Computing, Prvacy, Security, Risk and Trust, pp.819-826.

[2] Andrea Capitanelli, Alessandra Papetti, Margherita Peruzzini, Michele Germani.(2014). A Smart Home Information Management Model for Device Interoperability Simulation, 24th CIRP Design Conference, Vol.21, pp.64-69.

[3] Andreas Kamilaris, Vlad Trifa, Andreas Pitsillides.(2011). HomeWeb:An Application Framework for Web-based Smart Homes, IEEE-Telecommunications(ICT) 18th International Conference on.

[4] Andrew Whitmore, Anurag Agarwal, Li Da Xu.(2015). The Internet of Things-A Survey of Topics and Trends, Information Systems Frontiers, Vol.17, No.2, pp.261-274.

[5] EunA Kim, KwangSoo Kim, ChoonSeong Leem, ChoongHyung Lee.(2015). A Study on Development and Application of Taxonomy of Internet of Things Service, Journal of Society for e-Business Studies, Vol.20, No.2, pp.107-123.

[6] EunGi Hong. (2015). Global IoT opportunity 2014 and 2024. In IT Daily. Retrieved December 24, 2016, from http://www.itdaily.kr/news/articleView.html?idxno=62902.

[7] Felix Wortmann, Kristina Flu“chter.(2015). Internet of Things Technology and Value Added, Business Information System Engineering, Vol.57, No.3, pp.221-224.

[8] Gartner.(2014). Gartner Says 4.9 Billion Connected 'Things' Will Be in Use in 2015, In Newsroom. Retrieved December 21, 2016, from http://www.gartner.com/newsroom/id/2905717.

[9] Google Trends.(2016). Internet of Things based Smart Home Service. Retrieved December 20, 2016, from https://www.google.co.kr/trends/explore?date=all\&q=smart\%20home.

[10] Haines, V., Mitchell, V., Cooper, C. and Maguire, M.(2007).Probing User Values in the Home Envrionment within a Technology Driven Smart Home Project, Personal and Ubiquitos Computing, Vol.11, No.5, pp.349-359. 
[11] HoonYoung Lee.(2013). Statistical Packages for the Social Sciences(2nd Edition), Published by ChungRam, pp.368-389.

[12] HyangSook Kim, HyoChang Kim, YongGu Ji.(2015). User Requirement Elicitation for U-City Residential Environment : Concentrated on Smart Home Service, Journal of Society for E-Business Studies, Vol.20, No.1, pp.167-182.

[13] Jayavardhana Gubbi,Rajkumar Buyya, Slaven Marusic, Marimuthu Palaniswami.(2013). Internet of Things(IoT): A Vision, Architectural Elements, and Future Directions, Future Generation Computer Systems, Vol.29, No.7, pp.1645-1650.

[14] Jong Yoon Lee, JangSun Hong, JooHyeon Yoon.(2015). An Exploratory Study of the Early Users of the Internet of Things Using, Journal of Korean Society for the Scientific Study of Subjectivity, Vol.30, No.30, pp.89-107.

[15] JooHyun Park, HanYoung Ryoo.(2016). User Value Factors of Internet of Things(IoT) Service, The Human Computer Interaction Society of Korea, Vol.11, No.22, pp.23-30.

[16] Kyung Choi, Mihui Kim.(2016). Research on Convergence of Internet of Things and Cloud Computing, Journal of Korea Contents Association, Vol.16, No.5, pp.1-12.

[17] Pedro Castillejo, José-Fernán Martínez, Lourdes López, and Gregorio Rubio.(2013). An Internet of Things Approach for Managing Smart Services Provided by Wearable Devices, International Journal of Distributed Sensor Networks, Vol.2013, No.190813, pp.2-9.

[18] SeongHun Lee, MinSup Choi.(2015). A Study on Influence of Trait Values over User Satisfaction of Echo-Boomer Living with Smart-Home, Journal of Korea Real Estate Anlaysis Association, Vol.21, No.1, pp.103-131.

[19] Stephenson, W.(1969). Foundation of Communication Theory. Psychological Record, Vol.19, No.1, pp.65-82.

[20] TaeSeung Ha, JiHong Jung, SungYong Oh.(2006), Method to Analyze User Behavior in Home Envrionment, Personal and Ubiquitous Computing, Vol.10, No.2, pp.110-121.

[21] Treffyn Lynch Koreshoff, Toni Robertson, Tuck Wah Leong.(2013), Internet of Things: a review of literature and products, Proceeding OzCHI'13, Australian Computer-Human Interaction Conference, pp.335-344.

[22] WooSoo Jeong, SaHyuk Kim, KyungSik Min.(2013). An Analysis of the Economic Effects for the IoT Industry, Journal of Korean Society for Internet Information, Vol.14, No.5, pp.119-128.

\section{Authors}

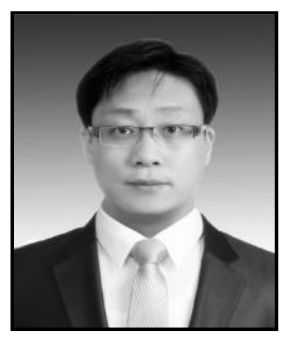

Ph.D. Seong(Seung)Jeong Yoon received the B.S. degree in Computer Science from Konkuk Universtiy in 2001 and he received his Ph.D. in Management Information System from Kyung Hee University in 2014. He is currently an adjunct Professor of MIS at School of Business, Kyung hee University and he has worked as a principal consultant to the information technology consulting. His current research interests include IT service, Cloud computing, Information system audit, Big data, Internet of Things, and etc.

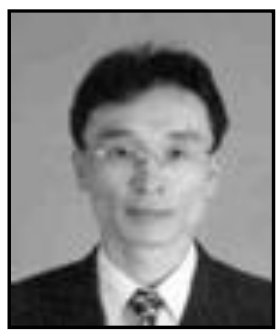

Jong-Bae Kim received his bachelor's degree (1995) and master's degree (2002) in Business Administration at University of Seoul, Seoul, doctor's degree in Computer Science at Soongsil University, Seoul (2006). Now he is a professor in the Graduate School of Software, Soongsil University in Seoul, Korea. His research interests focus on Software Engineering, and Open Source Software. 